RECEIVED

MAR 031997

OSTI

GA-A22349

CONF-960569--16

\title{
INVESTIGATION OF ELECTRON PARALLEL PRESSURE BALANCE IN THE SCRAPE-OFF LAYER OF DEUTERIUM-BASED RADIATIVE DIVERTOR DISCHARGES IN DIII-D
}

by

T.W. PETRIE, S.L. ALLEN, T.N. CARLSTROM, D.N. HILL, R. MAINGI, D.G. NILSON, M. BROWN, D.A. BUCHENAUER, T.E. EVANS, M.E. FENSTERMACHER, R.A. JONG, C.J. LASNIER, A.W. LEONARD, M.A. MAHDAVI, G.D. PORTER, M.R. WADE, and W.P. WEST

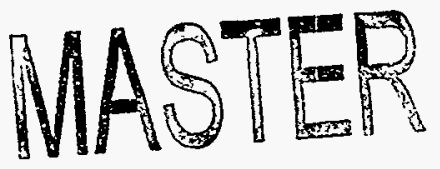

NITRINITION OF THS CSCUMENT IS UNLIMITED

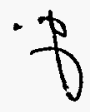

OCTOBER 1996 


\section{DISCLAIMER}

This report was prepared as an account of work sponsored by an agency of the United States Government. Neither the United States Government nor any agency thereof, nor any of their employees, makes any warranty, express or implied, or assumes any legal liability or responsibility for the accuracy, completeness, or usefulness of any information, apparatus, product, or process disclosed, or represents that its use would not infringe privately owned rights. Reference herein to any specific commercial product, process, or service by trade name, trademark, manufacturer, or otherwise, does not necessarily constitute or imply its endorsement, recommendation, or favoring by the United States Government or any agency thereof. The views and opinions of authors expressed herein do not necessarily state or refiect those of the United States Government or any agency thereof. 


\section{DISCLAIMER}

Portions of this document may be illegible in electronic image products. Images are produced from the best available original document. 


\section{INVESTIGATION OF ELECTRON PARALLEL PRESSURE BALANCE IN THE SCRAPE-OFF LAYER OF DEUTERIUM-BASED RADIATIVE DIVERTOR DISCHARGES IN DIII-D}

by

T.W. PETRIE, S.L. ALLEN, $\dagger^{\dagger}$ T.N. CARLSTROM, D.N. HILL, † R. MAINGI, † D.G. NILSON, $\dagger^{\dagger}$ M. BROWN, $\dagger^{\dagger}$ D.A. BUCHENAUER, $\diamond$ T.E. EVANS, M.E. FENSTERMACHER, ${ }^{\dagger}$ R.A. JONG, $\dagger^{\dagger}$ C.J. LASNIER, ${ }^{\dagger}$ A.W. LEONARD, M.A. MAHDAVI, G.D. PORTER, ${ }^{\dagger}$ M.R. WADE, $\Delta$ and W.P. WEST

This is a preprint of a paper to be presented at the 12th International Conference on Plasma Surface Interactions on Controlled Fusion Devices, May 20-24, 1996, Saint-Raphael, France and to be published in the Proceedings.

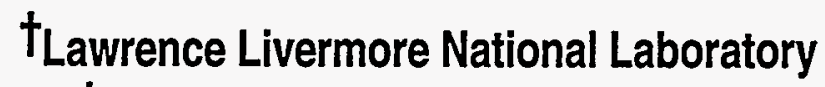
¥Oak Ridge Associated Universities

$\checkmark$ Sandia National Laboratories, Albuquerque

$\triangle$ Oak Ridge National Laboratory

Work supported by the U.S. Department of Energy

under Contract NoS. DE-AC03-89ER51114, W-7405-ENG-48, DE-AC05-960R22464, and DE-AC04-94AL85000

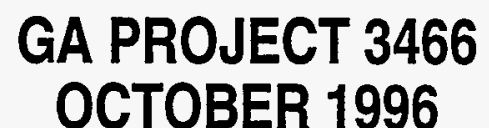




\section{ABSTRACT}

Electron density, temperature, and parallel pressure measurements at several locations along field lines connecting the midplane scrapeoff layer (SOL) with the outer divertor are presented for both attached and partially-detached divertor cases: $I_{p}=1.4 \mathrm{MA}$, q95 $=4.2$, and $P_{\text {input }}$ 6.7 MW under ELMing H-mode conditions. At the onset of the Partially Detached Divertor (PDD), a high density, low temperature plasma forms in the divertor SOL ("divertor MARFE"). The electron pressure drops by a factor of $\sim 2$ between the midplane separatrix and the $X$-point, and then an additional $~ 3-5$ times between the $X$-point and the outboard separatrix strike point. These results are in contrast to the attached (non-PDD) case, where electron pressure in the SOL is reduced by, at most, a factor of two between the midplane and the divertor target.

Divertor MARFEs generally have only marginal adverse impact on important $\mathrm{H}$-mode characteristics, such as confinement time. In fact, PDD discharges at low input power (i.e., approximately twice the $\mathrm{L}-\mathrm{H}$-mode threshold power) maintain good $\mathrm{H}$-mode characteristics until a high density, low temperature plasma abruptly forms inside the separatrix near the $\mathrm{X}$-point ("X-point MARFE"). Concurrent with the appearance of this X-point MARFE is a degradation in both energy confinement and the plasma fueling rate, and an increase in the carbon impurity concentration inside the core plasma. The formation of the X-point MARFE is consistent with a thermal instability resulting from the temperature dependence of the carbon radiative cooling rate in the range $\sim 7-30 \mathrm{eV}$. 


\section{INTRODUCTION}

We have previously shown that for attached ELMing $\mathrm{H}$-mode discharges the total plasma pressure near the outboard midplane $\left(\mathrm{n}_{\mathrm{e}} \mathrm{T}_{\mathrm{e}}+\mathrm{n}_{\mathrm{i}} \mathrm{T}_{\mathrm{i}}\right)$ was $\leq 2$ times the total pressure measured near the outboard separatrix strike point (OSP) [1,2]. To within the uncertainty of the measurements, and the uncertainties introduced by the assumptions that $\mathrm{T}_{\mathrm{i}}=\mathrm{T}_{\mathrm{e}}$ at the plasma/divertor tile interface and that the kinetic flow contribution along the field line is negligible, this result was consistent with plasma pressure balance.

When cold deuterium gas was added to ELMing H-mode discharges in sufficient quantity, however, the formation of a high density, highly radiative region located between the X-point and OSP was observed. Because the behavior of this high density, highly radiative region has shown several similarities to MARFE [3-5] behavior, we will find it convenient to refer to it as a "divertor MARFE", and we designate the operating regime after the divertor MARFE forms as the "Partially Detached Divertor" (PDD) regime [2]. The formation of the divertor MARFE in DIII-D generally has had only modest, if any, negative impact on energy confinement in the main plasma ( $\leq 10 \%$ of pre-puff) $[1,2,6]$. In addition to the divertor MARFE, other characteristics of the PDD regime in DIII-D are (1) factors of 3-5 times reduction in the peak heat flux and total incident power on the divertor surfaces compared to pre-puff times, (2) a significant reduction in particle flux near the OSP, and (3) plasma pressure balance along the flux surfaces that connect to the divertor is significantly violated $[1,2,6]$. While some details may differ, other tokamaks, such as Alcator C-MOD [7], JET [8], and ASDEX-Upgrade [9], have reported similar behaviors.

This study extends previous work by mapping electron density $\left(n_{e}\right)$, temperature $\left(T_{e}\right)$, and pressure $\left(\mathrm{P}_{e}\right)$ at several upstream locations between the $\mathrm{X}$-point and the divertor floor. This is now possible using the Divertor Thomson Scattering (DTS) diagnostic [10]. In Section 2, we outline the main experimental considerations. In Sections 3 and 4, we examine the divertor $\mathrm{n}_{\mathrm{e}}, \mathrm{T}_{\mathrm{e}}$, and $\mathrm{P}_{\mathrm{e}}$ distributions during ELMing H-mode operation for both PDD and non-PDD cases, respectively. In Section 5, we present an example of a high density, PDD H-mode plasma successfully operating at only $\sim 2$ times its $\mathrm{L}-\mathrm{H}$-mode power threshold value, and show that the abrupt formation of a high density region inside the separatrix near the $\mathrm{X}$-point ("X-point MARFE") may be an important step leading to the eventual degradation of its $\mathrm{H}$-mode properties. In this paper, it is important to distinguish between the "divertor MARFE" (which lies entirely outside the separatrix flux surface and may extend from the 
INVESTIGATION OF ELECTRON PARALLEL PRESSURE BALANCE IN THE

SCRAPEOFFLAYER OF DEUTERIUM-BASED RADIATIVE DIVERTOR

DISCHARGES IN DIII-D

T.W. Petrie, et al.

$\mathrm{X}$-point region down to the divertor floor) and the "X-point MARFE" (which lies entirely inside the separatrix flux surface near the $\mathrm{X}$-point). 


\section{EXPERIMENTAL CONSIDERATIONS}

A single-null divertor configuration was used in this study. The poloidal cross-section was generated by the EFITD magnetics code [11]. The locations of the principal diagnostics are also shown. The particle drift was toward the $\mathrm{X}$-point. No active particle pumping was used. In analyzing the following ELMing $\mathrm{H}$-mode plasmas, we only consider the Thomson scattering measurements made between ELMs.

The DTS line of sight is fixed. Hence, the X-point (and divertor plasma) must be radially swept across the line of sight in order to obtain a two-dimensional "picture" of the divertor $\mathrm{n}_{\mathrm{e}}$ and $T_{e}$. Details of this procedure are discussed elsewhere in this volume [12]. 


\section{ELMING H-MODE (NO D2 INJECTION)}

Figure 1 shows the electron density and temperature profiles for two horizontal slices across the outer divertor: $(\mathrm{a}, \mathrm{b})$ taken at $\mathrm{X}$-point height and $(\mathrm{c}, \mathrm{d})$ taken at a location just above the divertor floor; the $\mathrm{X}$-axis coordinate is normalized flux $\Psi_{\mathrm{N}}$ (see Fig. 1 caption). At the $\mathrm{X}$-point height, the electron density and temperature were approximately equal to their respective upstream midplane values [Fig. 1(a,b)].

Downstream near the divertor floor, the electron density values in the scrapeoff were $\sim 3$ times their corresponding midplane values [Fig. 1(c)]. The density dropped off rapidly in the private flux region (i.e., $\Psi_{N}<1.0$ ). On the other hand, the electron temperatures near the divertor floor were several times lower than their respective midplane values [Fig. 1(d)]; for example, $T_{e}$ near the OSP was $\approx 30 \mathrm{eV}$, which was $\sim 1 / 3$ times its midplane value. $T_{e}$ in the private flux region was only a few $\mathrm{eV}$.

Figure 2 shows electron pressure from the $\mathrm{X}$-point height down to the divertor floor along a SOL flux tube (a) adjacent to the separatrix $\left(\Psi_{\mathrm{N}}=1.000-1.004\right)$ and (b) along a flux tube farther out into the SOL $\left(\Psi_{N}=1.016-1.020\right)$. The divertor pressures are normalized to their respective midplane values. While there is scatter in the data, the electron pressure along both sets of field lines is approximately constant along their respective flux tubes and from the midplane to close to the divertor floor. 

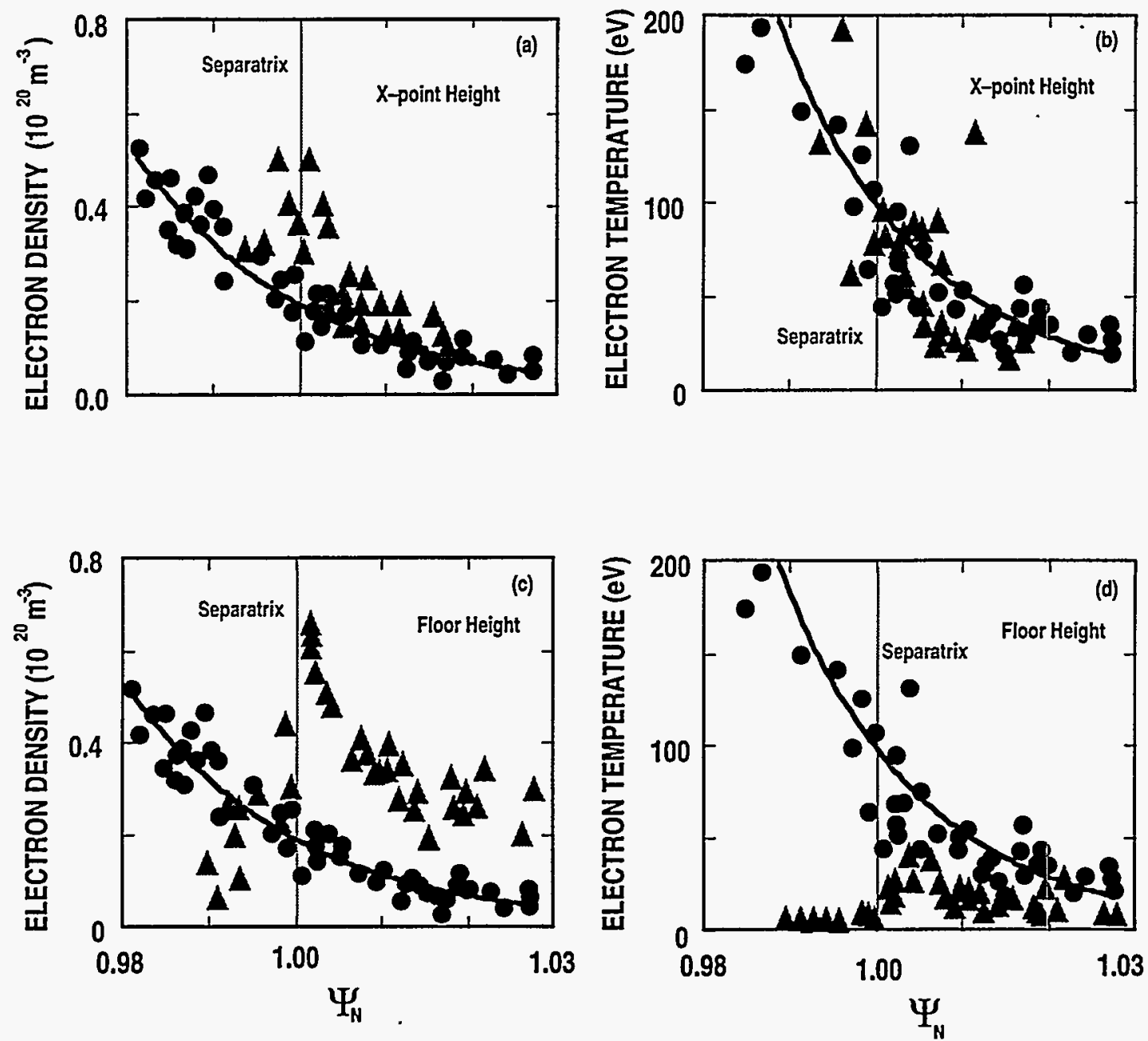

Fig. 1. ELMing $\mathrm{H}$-mode non-PDD case: The radial profiles for the electron density and temperature are taken at two heights above the divertor floor: $(a, b) X$-point height and $(c, d)$ near the floor. The $X$-axis uses normalized flux coordinates, where $\Psi_{N}>1$ is in the SOL and $\Psi_{N}=1.03$ would correspond to $\sim 0.01 \mathrm{~m}$ outside the separatrix at the midplane. The triangles represent the divertor data, while the circles represent the data taken near the midplane; the solid curve is the least-squares fit to the midplane data. The discharge parameters were: $I_{p}=1.4 \mathrm{MA}, B_{t}=2.1 \mathrm{~T}, a=0.6 \mathrm{~m}$, $q_{95}=4.2$, and $P_{\text {input }}=6.7 \mathrm{MW}$, which is $3-3.5$ times the $\mathrm{L}-\mathrm{H}-$ mode transition power. 

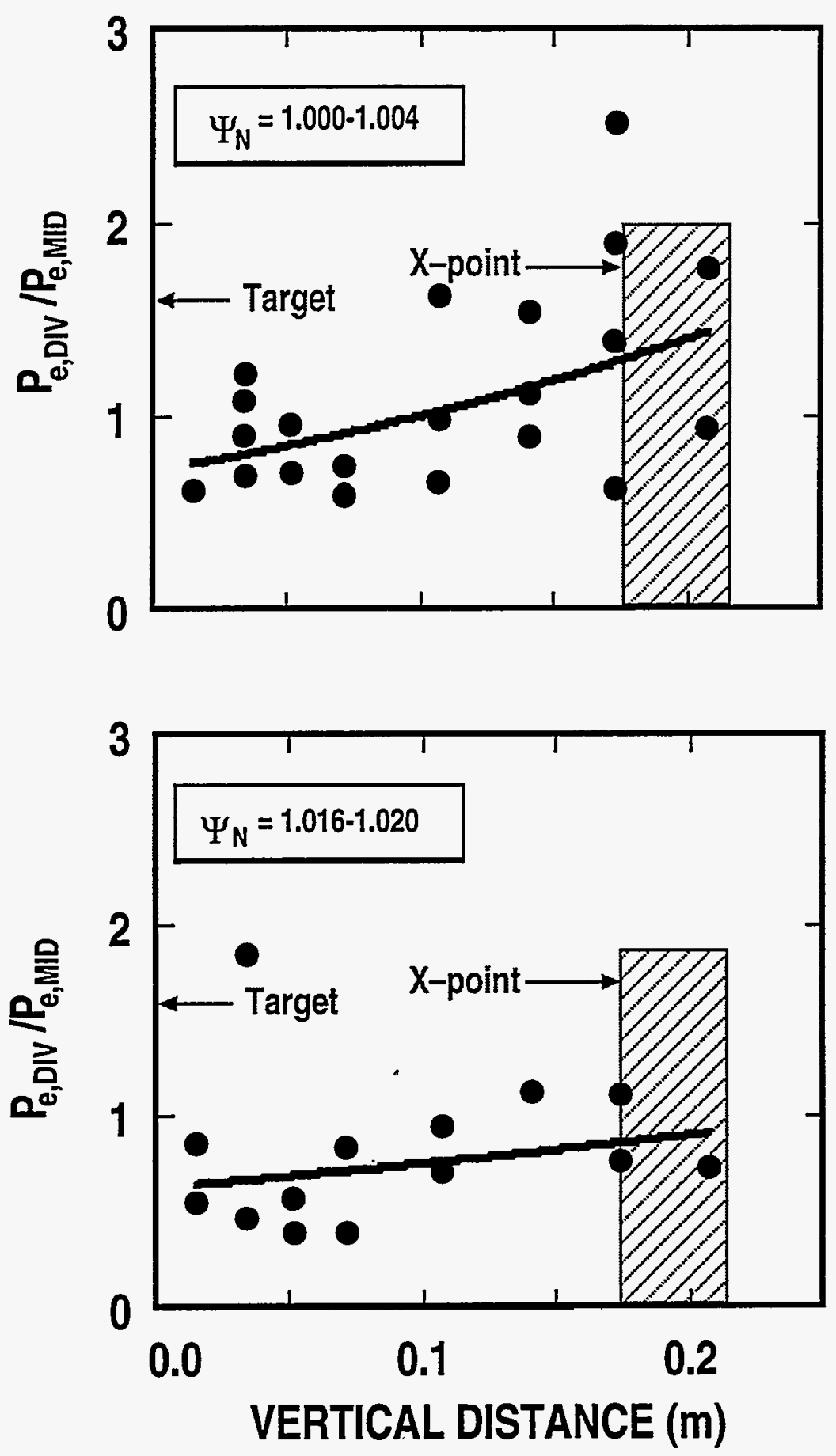

Fig. 2. ELMing $H$-mode non-PDD case: The electron pressures along SOL field lines (a) adjacent to the separatrix and (b) farther out into the scrapeoff are shown as a function of vertical height above the floor for the discharge described in Fig. 1. The divertor pressures ( $P_{e}$, DIV) are normalized to their corresponding midplane electron pressures $\left(P_{e}, M I D\right)$. Since the $X$-point height above the divertor floor changed slightly during the $X$-point sweep, the vertical $X$-point location has some variation, characterized by the cross-hatched region. 


\section{PDD ELMING H-MODE (WITH D2 INJECTION)}

The electron density, temperature and pressure in the PDD divertor have a much different distribution than those of the non-PDD ELMing H-mode. This is shown in Fig. 3 for a discharge with nearly identical parameters to the discharge discussed above, except that $\mathrm{D}_{2}$ gas injection has triggered PDD activity. Figure 3 shows $n_{e^{-}}$and $T_{e^{-}}$profile slices at the same vertical heights as those in Fig. 1. The electron density values across the $\mathrm{X}$-point slice were significantly higher than those corresponding to the midplane SOL (e.g., $\mathrm{n}_{\mathrm{e}}$ in the SOL near the $\mathrm{X}$-point was $>10$ times its midplane value [Fig. 3(a)]. The corresponding electron temperatures near the $\mathrm{X}$-point were much colder $(\sim 2 \mathrm{eV})$ than upstream near the midplane [Fig. 3(b)]. $\mathrm{T}_{\mathrm{e}}$ was higher $(\sim 5 \mathrm{eV})$ farther out into the $\mathrm{SOL}$, but this temperature was still much less than the corresponding upstream values.

At the divertor floor the electron density near the OSP dropped about an order of magnitude compared with its upstream value near the $\mathrm{X}$-point, but was comparable to its upstream midplane value Fig. 3(c). However, the electron density increased outboard of the OSP by at least an order of magnitude, similar to the results found earlier $[1,2,6]$ The characteristic electron temperature at this height was a few $\mathrm{eV}$.

Figure 4 shows the normalized electron pressure along the same two sets of SOL tubes as was shown in Fig. 2. Unlike the ELMing (non-PDD) case, there was some reduction $(\sim 2$ times) in electron pressure along SOL field lines adjacent to the separatrix between the midplane and X-point; a further reduction of a factor of $\sim 5$ was observed between the $\mathrm{X}$-point and the divertor floor. This reduction in electron pressure was not observed along field lines farther into the scrapeoff [Fig. 4(b)], where the data suggests that the electron pressure increased near the divertor floor and may have had a value higher than its upstream midplane value, qualitatively similar to previous observations [1]. 

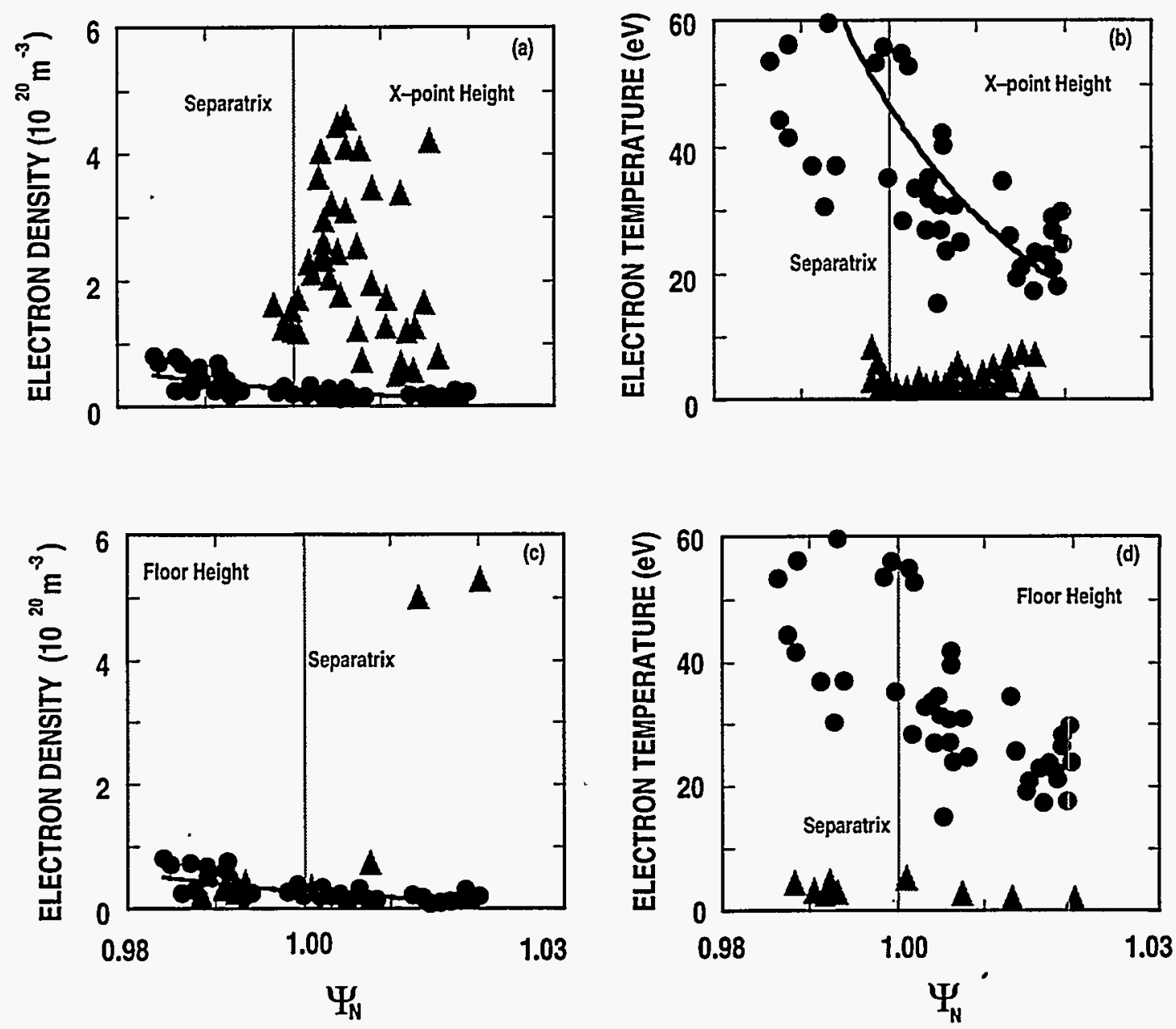

Fig. 3. ELMing H-mode $P D D$ case: The radial profiles for the electron density and the electron temperature are taken at the two heights discussed in Fig. 2. The discharge parameters were nearly identical to those of the non-PDD case: $\mathrm{I}_{\mathrm{p}}=1.4 \mathrm{MA}, \mathrm{B}_{\mathrm{t}}=2.1 \mathrm{~T}, \mathrm{a}=0.6 \mathrm{~m}, \mathrm{q}_{95} \quad=4.1$, and $\mathrm{P}_{\text {input }}=6.2 \mathrm{MW}$. 

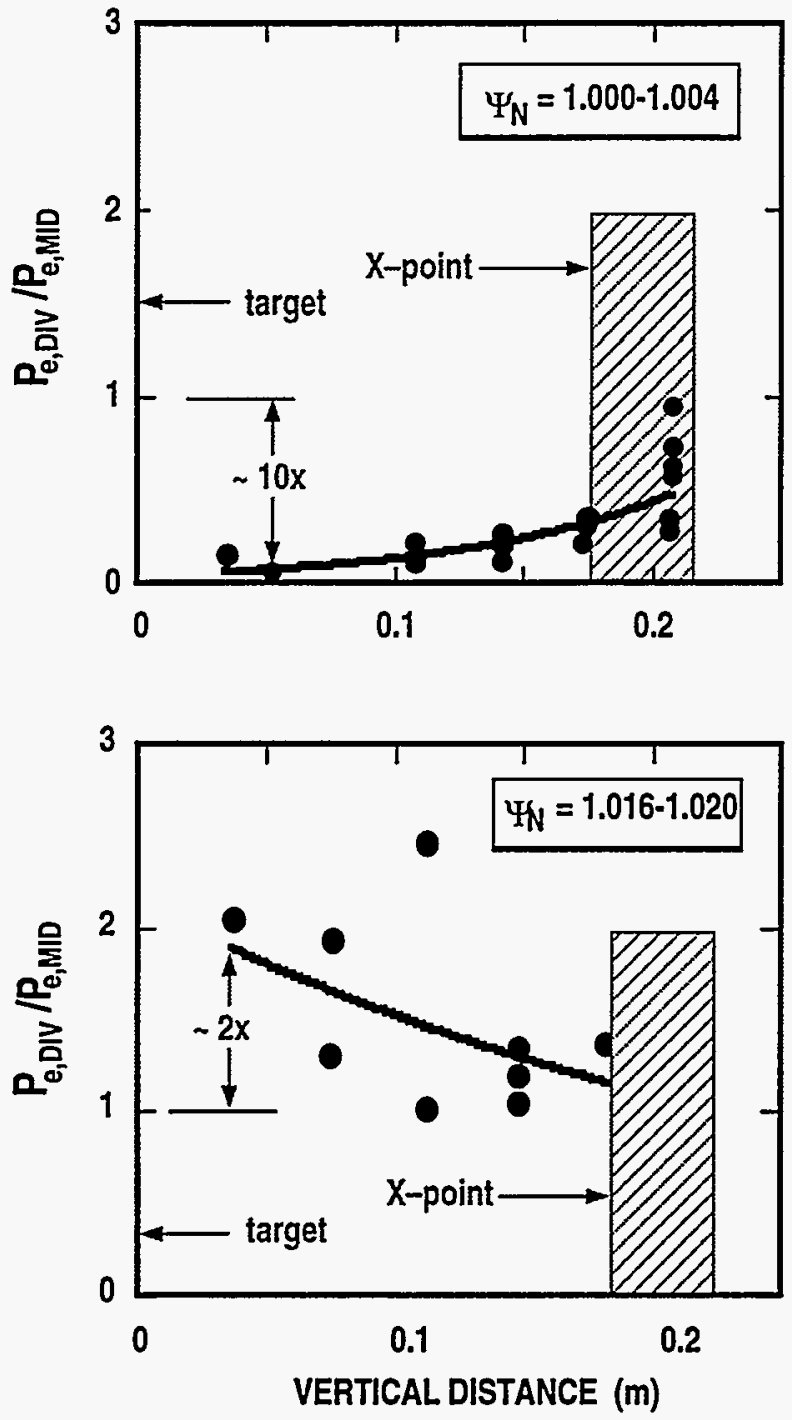

Fig. 4. ELMing $\mathrm{H}$-mode $P D D$ case: The electron pressures along SOL field lines (a) adjacent to the separatrix and (b) farther out into the scrapeoff are shown as a function of vertical height above the floor. The divertor electron pressures $\left(P_{E, D I V}\right)$ are normalized to their corresponding midplane pressures ( $\left.P_{e, M I D}\right)$. 


\section{HIGH DENSITY PDD OPERATION}

We now examine an evolving PDD discharge resulting from continuous $\mathrm{D}_{2}$ gas injection. This discharge differs from the above PDD plasma in three respects. First, because there was no $\mathrm{X}$-point sweeping during this shot, a time history at several divertor locations is available. Second, because this discharge has a lower $\mathrm{X}$-point than the discharge described above, several channels of the divertor Thomson lie inside the separatrix; this permits simultaneous Thomson scattering measurements near the X-point, both inside and outside the separatrix. Third, steady input power is $\sim 4 \mathrm{MW}$, which is only $\sim 2$ times the power required for the L$\mathrm{H}$-mode transition. Line-averaged electron density rose steadily throughout most of the PDD, which formed at $t \sim 2.5 \mathrm{~s}$, as evidenced by the density buildup along the outer divertor leg [ $\Delta \overline{\mathrm{n}}_{\mathrm{e}}$, Fig. 5(b)]. A roll-over in both line-averaged density and the energy confinement time, normalized to the ITER-89 value [13], was observed between $4.15 \mathrm{~s}$ and $4.36 \mathrm{~s}$ [Fig. 5(a,c)]. The electron density $n_{e, S O L}$, temperature $T_{e, S O L}$, and pressure $P_{e, S O L}$, which were measured in the SOL adjacent to the X-point, displayed the expected high density, low temperature and pressure "divertor MARFE" characteristics noted in Section 4 [Fig. 5(d,e,f)]. On the other

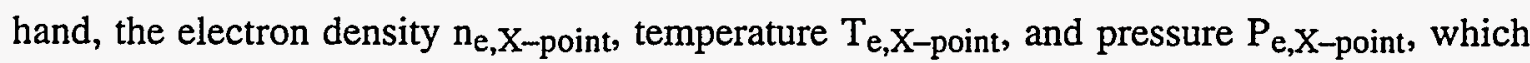
were also measured at a location adjacent to the $\mathrm{X}$-point (but inside the separatrix), displayed MARFE-like behavior only after $\sim 4.15$ s, i.e., an abrupt collapse in $\mathrm{T}_{\mathrm{e}}$ (from $\sim 25 \mathrm{eV}$ to $\sim 5$ $\mathrm{eV}$ ) and jump in $\mathrm{n}_{\mathrm{e}}$ (from $\sim 1 \times 10^{20} \mathrm{~m}^{-3}$ to $\sim 2 \times 10^{20} \mathrm{~m}^{-3}$ ). Finally, we note that the measured (CER) fraction of carbon in the core plasma increased during the X-point MARFE presence [Fig. 5(g)].

Additional analysis has shown a modest reduction in the midplane electron temperature

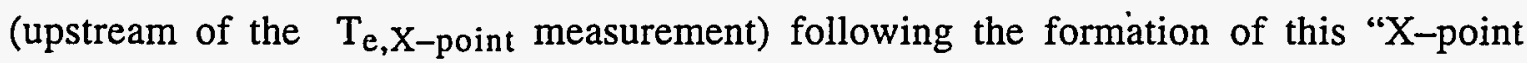
MARFE": $\mathrm{T}_{\mathrm{e}} \sim 70 \mathrm{eV}$ (prior to the $\mathrm{X}$-point MARFE) and $\mathrm{T}_{\mathrm{e}} \sim 50 \mathrm{eV}$ (during the $\mathrm{X}$-point MARFE). The electron pressure at this time was better preserved on the inside-separatrix flux surface than on the outside-separatrix surface. $\mathrm{P}_{\mathrm{e}, \mathrm{X}}$-point was roughly equal to its upstream midplane value before the formation of the X-point MARFE and $~ 70 \%$ of its midplane value after the $X$-point MARFE formation, while $P_{e}, S O L$ remained $\sim 1 / 3$ its upstream midplane pressure throughout. The absolute value of $\mathrm{P}_{\mathrm{e}, \mathrm{X} \text {-point }}$ after the formation of the $\mathrm{X}$-point MARFE, however, was a factor of $\sim 2-3$ times lower than prior to the formation of the $\mathrm{X}$-point MARFE. 
87483
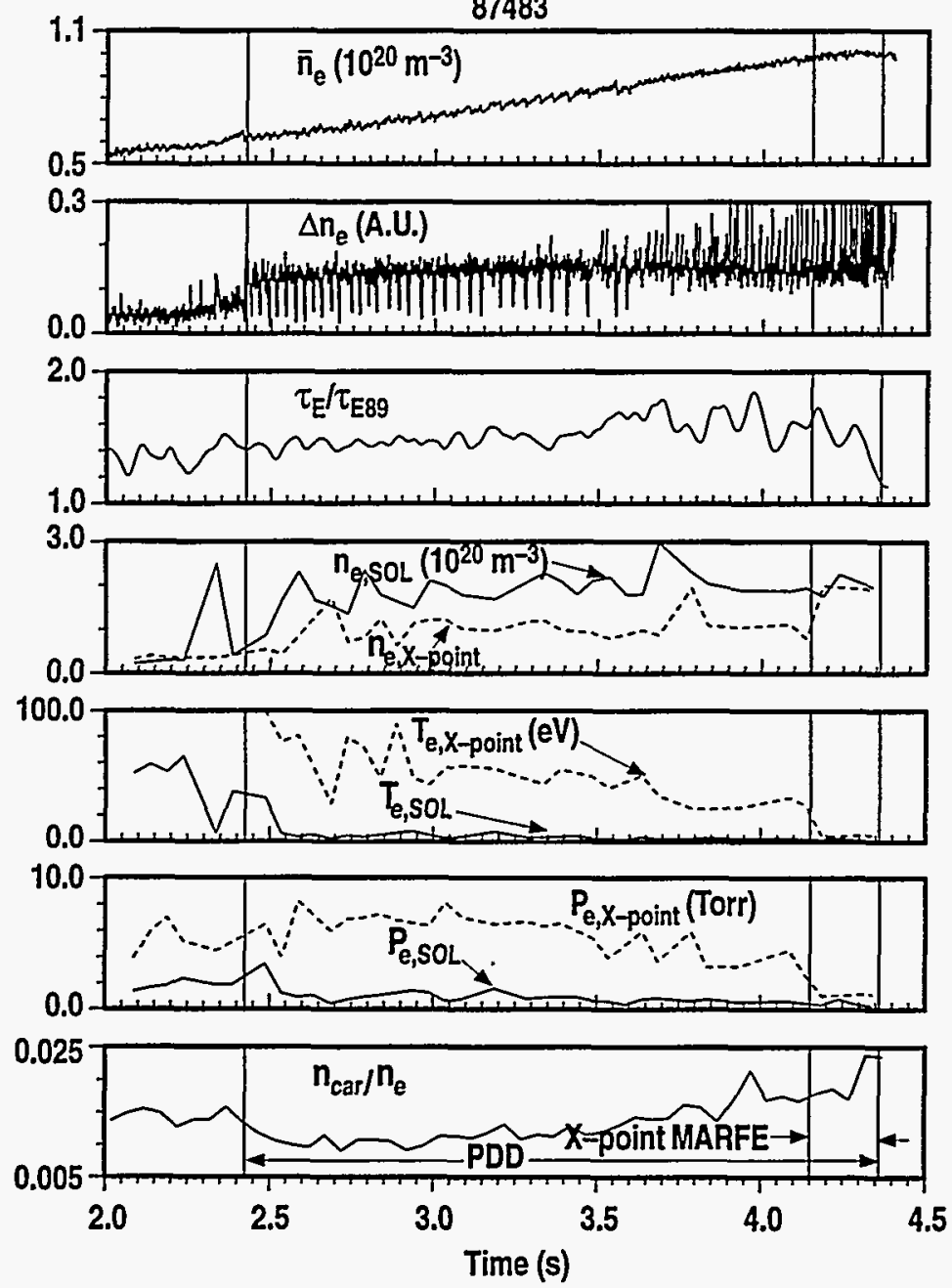

Fig. 5. Evolving PDD discharge: (a) $\bar{n}_{e}$ is the line-averaged density of the main plasma, (b) $\Delta \bar{n}_{e}$ is an indicator of PDD activity and density buildup along the outboard leg, (c) $\tau_{E} / \tau_{E 89}$ is the energy confinement time normalized to the ITER-89 L-mode scaling, (d) $n_{e, x-p o i n t}$ and $n_{e, S O L}$ are respectively the electron densities inside and outside the separatrix near the $X$-point, (e) $T_{e, x \text {-point }}$ and $T_{e, s O L}$ are respectively the electron temperatures inside and outside the separatrix near the $X$-point, (f) $P_{e, x-p o i n t}$ and $P_{e, S O L}$ are respectively the electron pressures inside and outside the separatrix near the $X$-point, and $(g) n_{c a r} / n_{e}$ is the fraction of carbon impurity in the core plasma, as determined by charge-exchange recombination. Discharge parameters: $I_{p}=1.4 \mathrm{MA}, \quad B_{t}=2.1 \mathrm{~T}, \quad a=0.6 \mathrm{~m}, q_{95}=4.2$, and $P_{\text {input }}=3.9 \mathrm{MW}, \mathrm{D}_{2}$ puff rate $=70 \mathrm{~T} \cdot 1 / \mathrm{s}$. 


\section{DISCUSSION}

Electron pressure balance was largely maintained in the scrapeoff layer of ELMing $\mathrm{H}$-mode non-PDD plasmas. On the other hand, pressure balance in the SOL was not maintained when the discharge is in the PDD regime. The electron pressure was significantly reduced between the midplane and the OSP, while it appeared to increase between the midplane and the "floor" for a flux tube farther out in the SOL. Coupled with data that has shown neutral pressure in the private flux region tens of mTorr during the PDD [1,2], such behavior implies momentum transfer across flux surfaces in the divertor SOL, possibly via charge-exchange or ion-neutral collisions [14-16]. These two processes should be relatively important at the cold divertor temperatures $(<5 \mathrm{eV})$ measured. (Feedback on neutral pressure in the private flux region has been shown, in fact, as an effective means of turning the PDD "on" and "off" [2].) While DIII-D [1] and other tokamaks [7,9,17] have previously reported cold temperatures at the divertor floor (using Langmuir probes), the DTS diagnostic shows that these "cold" temperatures extend well above the floor to at least the X-point height. Hence, the region where momentum transfer across flux surfaces might be of importance may be a significant fraction of the divertor volume.

In previous high power experiments in DIII-D [1,2,6], we showed that ELMing $\mathrm{H}$-mode PDD discharges could be operated over a fairly large range in line-averaged density $\left(\bar{n}_{e}\right)$. These discharges were at "high power" in the sense that the power levels used were several times the power level needed to trigger the $\mathrm{L}-\mathrm{H}$ transition. ELMing $\mathrm{H}$-mode PDD discharges were routinely triggered at $\sim 60 \%$ of the Greenwald density limit [18] and could be maintained up to $\sim 80 \%-90 \%$ of the Greenwald limit.

In this paper we demonstrated that PDD discharges at only twice the $\mathrm{L}-\mathrm{H}$-mode threshold power could be successfully operated over a density range comparable to the higher power cases. We were able to maintain $\tau_{\mathrm{E}} / \tau_{\mathrm{E} 89} \sim 1.6$ through most of the PDD regime, as long as the MARFE-like activity was confined to the divertor SOL. When the electron temperature inside the separatrix near the $\mathrm{X}$-point decreased to $\sim 25-30 \mathrm{eV}$ range, a pronounced drop-off

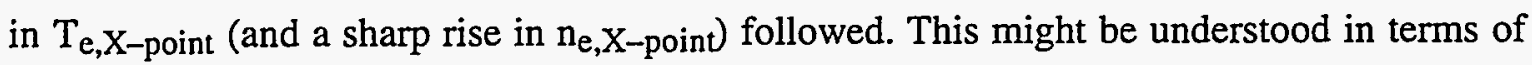
the behavior of carbon impurity radiation near the X-point. Recent studies of MARFE-like radiation during the PDD operation suggest that a significant contributor to radiated power in the $\mathrm{X}$-point region during PDD operation is carbon $(\sim 50 \%)$ [19]. While the cooling rate for the carbon impurity [20] decreases between $\mathrm{T}_{\mathrm{e}} \sim 100 \mathrm{eV}$ and $\sim 30 \mathrm{eV}$, it increases by 2-3 orders of magnitude from $\mathrm{T}_{\mathrm{e}} \sim 25 \mathrm{eV}$ to $\sim 7 \mathrm{eV}$. This suggests (1) that an $\mathrm{X}$-point plasma with a significant carbon impurity component may become thermally unstable (and subject to 
MARFE condensation) when $\mathrm{T}_{\mathrm{e}, \mathrm{X} \text {-point }}$ drifts down to the $25-30 \mathrm{eV}$ range (as it did during the extended gas puffing in this case) and (2) that one can expect the $X$-point region to maintain thermal stability if $T_{e, X-p o i n t}-40-90 \mathrm{eV}$. This issue is now under quantitative investigation [21].

After the MARFE had penetrated the X-point separatrix region, $\tau_{\mathrm{E}}$ and the rate of rise in $\overline{\mathrm{n}}_{\mathrm{e}}$ were measurably reduced. Radiated power from inside the separatrix near the $\mathrm{X}$-point was observed to go up during this time. The carbon impurity concentration in the main plasma increased significantly following the formation of the X-point MARFE. While the processes leading to this influx are still under investigation, one can hypothesize that the drop in $\mathrm{T}_{\mathrm{e}, \mathrm{X} \text {-point }}$ to only a few $\mathrm{eV}$ may have made the core plasma much more accessible to the carbon impurity influx. 


\section{CONCLUSION}

The onset of the PDD is characterized by the formation of a high density, very low temperature divertor plasma ("divertor MARFE"), part of which may lie adjacent to the $\mathrm{X}$-point (but outside the separatrix). The divertor MARFE appears to have only marginal effect on energy confinement and the rate of rise in $\bar{n}_{e}$. In fact, the carbon impurity concentration in the main plasma is reduced following the PDD transition. However, continued deuterium gas puffing during the PDD may eventually lead to the formation of a high density, low temperature region inside the separatrix near the $\mathrm{X}$-point (" $\mathrm{X}$-point MARFE"). When this happens, degradations in energy confinement, fueling effectiveness, and core plasma cleanliness are observed. We suspect that the formation of an $\mathrm{X}$-point MARFE is due to the destabilizing influence of the carbon cooling rate behavior which occurs

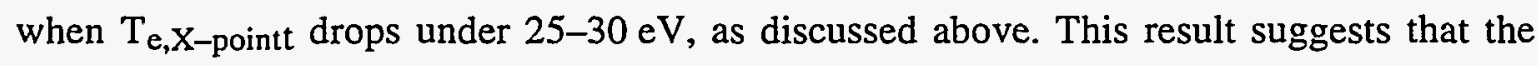
density operating range of high density PDD $\mathrm{H}$-mode divertor discharges might be increased, if a critical $\mathrm{X}$-point temperature can be maintained. For tokamaks which are dominated by intrinsic impurities other than carbon, this "critical" temperature range may be different. 


\section{REFERENCES}

[1] T.W. Petrie, D. Buchenauer, D. Hill, et al.J. Nucl. Mater. 196-198 (1992) 848.

[2] T.W. Petrie, D.N. Hill, S.L. Allen, et al., "Radiative Divertor Experiments in DIII-D With $D_{2}$ Injection," General Atomics Report GA-A21879, May 1995 (to be published in Nucl. Fus.)

[3] D. Baker, R. Snider, and M. Nagami, Nucl. Fusion 22 (1982) 807.

[4] B. Lipschultz, B. LaBombard, E.Marmar, et al., Nucl. Fusion 24 (1984) 977.

[5] J. Drake, Phys. Fluids, 30 (1987) 2429.

[6] T.W. Petrie, D.N. Hill, D. Buchenauer, et al., Proc. 18th European Conf. on Contr. Fusion and Plasma Physics, Berlin, Vol. 15C, part III (1991) 237.

[7] B. Lipschultz, J. Goetz, B.LaBombard, et al., J. Nucl. Mater. 220-222 (1995) 50.

[8] G. Janeschitz, S. Clement, N. Gottardi, et al., Proc, 19th European Conf. on Contr. Fusion and Plasma Physics, Innsbruck, Vol 16C, part II (1993) 727.

[9] M. Laux, Proc. 20th European Conf. on Cont. Fusion and Plasma Heating, Lisbon, Vol 17C, part II (1993).

[10] T.N. Carlstrom, D.G. Nilson, D.N. Hill, et al., "Initial Operation of the Divertor Thomson Scattering Diagnostic on DIII-D," General Atomics Report (submitted to Rev. Sci. Instr.).

[11] L.L. Lao, H. St John, R. Stambaugh, A. Kellman, and W. Pfeiffer, Nucl. Fusion 25 (1985) 1611.

[12] M.E. Fenstermacher, et al., (published in this issue).

[13] P. Yushmanov, T. Takizuka, K. Riedel, et al., Nucl. Fusion 30 (1990) 929.

[14] P.C. Stangeby, Nucl. Fusion 33 (1993) 1695.

[15] Ph. Ghendrih, T.W. Petrie, C.J. Lasnier, et al., J. Nucl. Mater. 220-222 (1995) 305. 
[16] Ph. Ghendrih, H. Capes, Proc. 15th International Conf. on Plasma Physics and Contr. Nucl. Fusion Research, Seville, Vol. 3 (1994) 441.

[17] G.F. Matthews, et al., U.S. DOE/Garching Divertor Workshop (1993).

[18] M. Greenwald, J. Terry, S. Wolfe, et al., Nucl. Fusion 28 (1988) 2199.

[19] R. Wood, R. Isler, and D Whyte (private communications).

[20] D.E. Post, R. Jensen, C. Tartar, et al., "Steady State Radiative Cooling Rates For LowDensity High Temperature Plasmas," Atomic Data and Nuclear Data Tables 20 (1977) 397-439.

[21] M.A. Mahdavi (private communication). 


\section{ACKNOWLEDGMENT}

Work supported by the U.S. Department of Energy under Contract Nos. DE-AC0389ER51114, W-7405-ENG-48, DE-AC05-OR22464, and DE-AC04-94AL85000. 